\title{
Environmental pollutants and stroke-related hospital admissions
}

\author{
Poluentes ambientais e internações devido a \\ acidente vasculoencéfalico
}

1 Departamento de Medicina, Universidade de Taubaté, Taubaté, Brasil. 2 Programa de Pós-graduação em Ciências Ambientais, Universidade de Taubaté, Taubaté, Brasil.

Correspondence L. F. C. Nascimento Departamento de Medicina, Universidade de Taubaté. Rua Durval Rocha 500

Guaratinguetá, $S P$ 12515-710, Brasil. luiz.nascimento@feg.unesp.br

\section{Abstract}

Some effects of environmental pollution on human health are known, especially those affecting the respiratory and cardiovascular systems. The current study aimed to estimate these effects on the production of hospital admissions for stroke. This was an ecological study using hospital admissions data in São José dos Campos, São Paulo State, Brazil, with diagnosis of stroke, from January 1, 2007, to April 30, 2008. The target pollutants were particulate matter, sulfur dioxide, and ozone. Use of a Poisson linear regression model showed that same-day exposure to particulate matter was associated with hospitalization for stroke (RR $=1.013 ; 95 \% C I$ : 1.001-1.025). An increase of $10 \mu \mathrm{g} / \mathrm{m}^{3}$ in this pollutant increased the risk of hospitalization by $12 \%(R R=1.137 ; 95 \% C I$ : 1.014-1.276). In the multi-pollutant model, it was thus possible to identify particulate matter as associated with hospitalization for stroke in a medium-sized city like São José dos Campos.

Air Pollution; Stroke; Particulate Matter; Sulfur Dioxide; Ozone
Luiz Fernando Costa Nascimento 1,2 Juliana B. Francisco 1 Marielle Beatriz R. Patto 1 Angélica M. Antunes 1

\section{Introduction}

Several studies have shown the deleterious effects of exposure to air pollution on human health. Olmo et al. 1 list the main Brazilian and non-Brazilian studies that show the association between exposure to air pollution and human morbidity. These studies also show the association between exposure to air pollution and human mortality.

Two recent national studies conducted in a medium-sized city, show the effects of exposure to pollutants from data collected from ischemic heart disease hospitalizations 2 as well as data collected from hospital mortalities, due to respiratory diseases 3 .

Among cardiovascular diseases, stroke is a common syndrome in adults. Stroke is also a major cause of human morbidity and mortalities, worldwide. In 2008, more than 90,000 hospital admissions, due to stroke, were reported in Brazil. There are 21,000 records of hospital admissions, due to stroke, in the State of São Paulo alone (Departamento de Informática do SUS. http://www. datasus.gov.br, accessed on 10/Nov/2000); mortality rates in the same year were 88,000 nationwide for Brazil and 19,000 for the State of São Paulo (Departamento de Informática do SUS. http://www. datasus.gov.br, accessed on 10/Nov/2000).

In a time-series study using stroke hospitalization reports, an association has been demonstrated between air pollution and stroke hospitalizations. This time-series study indicated that the 
air pollutants of particulate matter and nitrogen dioxide were responsible for both ischemic and hemorrhagic stroke hospitalizations ${ }^{4}$. Another study of Medicare recipients, demonstrated the role of particulate matter in the genesis of ischemic stroke. However, the results of the same study also concluded, that particulate matter was not a factor in cases of hemorrhagic stroke 5 . Both studies included daily levels of air pollution in lags up to 2 days before hospital admissions. A study developed in Sweden shows an associated risk between exposure to particulate matter and hospital admissions. The same study showed that there was a $13 \%$ increase in this risk when particulate matter concentrations were above $30 \mu \mathrm{g} / \mathrm{m}^{3} 6$. Another study in Canada, demonstrated that exposure to air pollution was associated with hospital admissions, particularly in regards to hemorrhagic strokes 7 .

The lag structure approach has been used to study the effects of pollutants at the onset of strokes. It has also been used in other studies of heart 2,8 and respiratory disease 9 . The lag structure approach is used, because exposure to air pollutants may not only be evident on the same day of the onset of the stroke, but also in the previous days before stroke hospitalizations.

The aim of this study was to assess the levels of pollutant particulate matter under 10 microns in diameter $\left(\mathrm{PM}_{10}\right)$, sulfur dioxide $\left(\mathrm{SO}_{2}\right)$ and ozone $\left(\mathrm{O}_{3}\right)$ in the genesis of stroke associated hospital admissions in the city of São Jose dos Campos, São Paulo, Brazil.

\section{Methodology}

This is an ecological time-series study using data collected from stroke associated hospital admissions in the city of São Jose dos Campos, São Paulo State, Brazil.

The stroke diagnosis used, is in accordance with the International Classification of Diseases, $10^{\text {th }}$ revision, codes I60 to I64.

\section{Study area}

This study was conducted in São José dos Campos, a medium-sized city located $80 \mathrm{~km}$ from São Paulo, between two mountain ranges. The population of São José dos Campos is approximately 700,000 inhabitants. São José dos Campos is located at an altitude is of $600 \mathrm{~m}$ above sea level and it is geographically located at latitude $23^{\circ} 11^{\prime} \mathrm{S}$ and longitude $45^{\circ} 53^{\prime} \mathrm{W}$. The city has around 1,100 industrial establishments, with emphasis on automobile manufacturing, aerospace and pharmaceutical industries, and oil refinery. São José dos
Campos is crossed by the Dutra Highway. This is the most important highway in Brazil. The Dutra Highwayis particularly noted for having heavy truck and bus traffic.

\section{Data collection}

This study included subjects of both sexes, 50 years of age and older, living in São José dos Campos. This study was conducted between January 1, 2007 and April 30, 2008. Information on hospital admissions was obtained from the Health Informatics Department web page (DATASUS. http://www.datasus.gov.br, accessed on 10/ Nov/2000).

Estimated levels of pollutants consisted of: $\mathrm{PM}_{10}, \mathrm{SO}_{2}$ and $\mathrm{O}_{3}$. This data was obtained from the measuring station of the São Paulo State Environmental Agency (Companhia de Tecnologia de Saneamento Ambiental - CETESB) in São Jose dos Campos, which also provided the values for temperature and relative humidity.

\section{Data analysis}

A database was built with daily data consisting of stroke associated hospital admissions, estimated levels of each indicated pollutant and climate variables. The study took into consideration lags of zero, one and two days. The generalized linear model (GLM) of Poisson regression was chosen because hospital admissions are a discret counting event. The generalized linear models were first introduced by Nelder \& Wedderburn 10 and include the models of simple and multiple linear regressions, logistic regression, Poisson regression and many others, such as log-linear models for categorical data.

The basic ingredient of each of these models is a monotonic and differentiable function $g$. If $g$ is the logarithmic function, and if $\mathrm{Y}$, the response variable, has a Poisson distribution, then, the resulting model is the Poisson regression model. Among other applications, the Poisson regression model is commonly used to assess the effects of pollution ${ }^{11}$. In this model, if $\beta \mathrm{i}$ is a coefficient obtained by Poisson regression, then $\exp (\Delta \beta \mathbf{i})$ represents the relative risk of occurrence of an event of interest (e.g. death or hospitalization).

The daily number of stroke-related hospital admissions was considered to be the dependent variable in the generalized linear Poisson regression models and the concentration of the pollutants was considered to be the independent variable. After conducting sensitive analyses, four degrees of freedom (d.f.) were adopted to smooth out the time trend. The number of d.f. for the natural spline of time trend was selected 
to minimize the autocorrelation in the residuals and the Akaike Information Criterion (AIC).

Assuming that the effect of temperature observed for respiratory diseases, presents the same pattern in stroke cases, linear terms were used to control the effects of temperature and humidity on the number of stroke-related hospital admissions. The lag structures between air pollution and health have been analyzed, using different approaches and time lags. In this study, the lag structure was tested from 2 to 0 days before hospital admission, using a third-degree polynomial distributed lag model. The model imposes constraints, but gives enough flexibility to estimate a biologically plausible lag structure, and allows for better control of multicollinearity than the unconstrained lag model.

The models were built with a single pollutant (single model), and the three pollutants simultaneously (multi-pollutant model) adjusted for maximum temperature and relative humidity. Stata, version 9 (Stata Corp., College Station, USA), was used for the statistical analysis.

The results were expressed as a relative risk estimate. The percentage increase in risk (PIR) for stroke hospitalization was considered, according to a $10 \mu \mathrm{g} / \mathrm{m}^{3}$ increase $(\Delta)$ of $\mathrm{PM}_{10}$ concentration, in accordance with the expression; PIR $(\%)=(\exp$ (coeff $\left.{ }^{*} \Delta\right)$ - 1), with coeff being the coefficient obtained by Poisson regression.

\section{Results}

The period of study was 487 days, during which, there were 407 hospitalizations due to stroke, with a daily average of 0.84 hospitalizations $(\mathrm{SD}=0.96)$. The $\mathrm{PM}_{10}$ daily average was $24.4 \mu \mathrm{g} / \mathrm{m}^{3}$ $(\mathrm{SD}=12.0)$. The $\mathrm{SO}_{2}$ daily average was $3.2 \mu \mathrm{g} / \mathrm{m}^{3}$ $(\mathrm{SD}=3.1)$. The $\mathrm{O}_{3}$ daily average was $85.5 \mu \mathrm{g} / \mathrm{m}^{3}$
$(\mathrm{SD}=36.2)$. The average daily humidity was $87.5 \%$ $(\mathrm{SD}=6.4)$. The average daily maximum temperature was $29.1^{\circ} \mathrm{C}(\mathrm{SD}=3.5)$. Table 1 shows that the pollutants have a strong correlation between themselves and between climatic variables.

There were 88 non-consecutive missing data entries for $\mathrm{SO}_{2}(17.5 \%)$ six missing data entries for $\mathrm{PM}_{10}$ and five missing data entries for $\mathrm{O}_{3}$. The interquartile difference was $16 \mu \mathrm{g} / \mathrm{m}^{3}$ for particulate matter, $2 \mu \mathrm{g} / \mathrm{m}^{3}$ for sulfur dioxide and $50 \mu \mathrm{g} / \mathrm{m}^{3}$ for $\mathrm{O}_{3}$.

Table 2 shows the relative risk and 95\% confidence interval obtained by coefficients of Poisson regression, with the single pollutant model and the multi-pollutant model, on the same day (lag 0), with a lag of one day (lag 1) and a lag of two-days (lag 2). Particulate matter was the only pollutant associated with stroke hospitalization in both the single pollutant model and the multipollutant model, on concurrent days (lag 0). Sulfur dioxide lost its statistical significance in the multi-pollutant model. It can be observed that the relative risk for hospitalization due to stroke is approximately $2 \%$.

\section{Discussion}

To the best of our knowledge, this is the first study in Brazil, on the association between environmental pollutants and hospital admissions for ischemic stroke, hemorrhagic stroke and stroke in unspecified categories. The study used data from DATASUS, as in other studies 2,8,9,12.

This study did not discriminate according to the hemorrhagic and ischemic stroke categories as described by Tsai et al. 4 and Wellenius et al. 5 . The option to use linear models in place of additive models is due to the fact that Conceição et al. 13 demonstrated that there was little difference

Pearson correlation coefficients between air pollutants, weather conditions and hospital admission duringthe study period. São José dos Campos, São Paulo State, Brazil, 2007 to 2008.

\begin{tabular}{|c|c|c|c|c|c|c|}
\hline & Admission & $\mathrm{PM}_{10}$ & $\mathrm{SO}_{2}$ & $\mathrm{O}_{3}$ & Temperature $\left({ }^{\circ} \mathrm{C}\right)$ & Humidity (\%) \\
\hline Admission & 1.00 & & & & & \\
\hline $\mathrm{PM}_{10}$ & 0.11 * & 1.00 & & & & \\
\hline $\mathrm{SO}_{2}$ & 0.08 & $0.48 * \star$ & 1.00 & & & \\
\hline $\mathrm{O}_{3}$ & -0.04 & $0.47 \star \star$ & $0.26 * \star$ & 1.00 & & \\
\hline Temperature $\left({ }^{\circ} \mathrm{C}\right)$ & -0.10 * & -0.04 & $-0.21 * \star$ & $0.45 * \star$ & 1.00 & \\
\hline Humidity (\%) & 0.04 & $-0.45 * \star$ & $-0.16 * *$ & $-0.59 * *$ & $-0.39 * *$ & 1.00 \\
\hline
\end{tabular}

* $\mathrm{p}<0.05$

$\star \star p<0.01$ 
Relative risk with respective $95 \%$ confidence interval $(95 \% \mathrm{Cl})$ through a single and multipollutant modeling. São José dos Campos, São Paulo State, Brazil, 2007 to 2008.

\begin{tabular}{ccc}
\hline & Single-pollutant model $(95 \% \mathrm{Cl})$ & Multipollutant model $(95 \% \mathrm{Cl})$ \\
\hline Lag 0 & & \\
$\mathrm{PM}_{10}$ & $1.014(1.006-1.023)$ & $1.013(1.001-1.025)$ \\
$\mathrm{SO}_{2}$ & $1.029(1.000-1.060)$ & $1.014(0.980-1.049)$ \\
$\mathrm{O}_{3}$ & $1.001(0.998-1.005)$ & $0.998(0.994-1.003)$ \\
$\mathrm{Lag} 1$ & $1.005(0.996-1.014)$ & \\
$\mathrm{PM}_{10}$ & $1.011(0.978-1.044)$ & $1.005(0.993-1.017)$ \\
$\mathrm{SO}_{2}$ & $0.999(0.996-1.003)$ & $1.011(0.974-1.047)$ \\
$\mathrm{O}_{3}$ & $1.009(0.997-1.017)$ & $0.996(0.992-1.001)$ \\
$\mathrm{Lag}_{2}$ & $1.022(0.992-1.052)$ & $1.008(0.996-1.020)$ \\
$\mathrm{PM}_{10}$ & $0.999(0.996-1.004)$ & $1.018(0.984-1.052)$ \\
$\mathrm{SO}_{2}$ & & $0.996(0.991-1.001)$ \\
$\mathrm{O}_{3}$ & & \\
\hline
\end{tabular}

in the estimated values in cases of hospitalization due to respiratory diseases. This type of approach (the generalized linear model), was used successfully to estimate the role of exposure to pollutants generated by burning biomass in hypertension hospitalizations 14 .

In our study, ozone concentrations exceeded the acceptable value of $160 \mu \mathrm{g} / \mathrm{m}^{3}$ on 16 occasions for 21 days in $\mathrm{PM}_{10}$, whose values are of $50 \mu \mathrm{g} / \mathrm{m}^{3}$ and $\mathrm{SO}_{2}$ and do not exceed the values recommended by the National Council of the Environment (Conselho Nacional do Meio Ambiente - CONAMA. http://www.mma.gov.br/port/ conama $/$ legipesq.cfm?tipo $=3 \&$ numero $=03 \&$ ano $=$ 1990\&texto $=$, accessed on 20/Oct/2011).

When analyzed, in the single pollutant model, on the concurrent day (lag 0), stroke hospitalizations were associated with exposure to $\mathrm{SO}_{2}$ and $\mathrm{PM}_{10}$. However, in the single pollutant model, when lags of one day (lag 1) and two days (lag 2) were considered, stroke hospitalizations were not associated with exposure to $\mathrm{SO}_{2}$ and $\mathrm{PM}_{10}$. When analyzed in the multi-pollutant model, on the concurrent day (lag 0), stroke hospitalizations, were only associated with exposure to $\mathrm{PM}_{10}$. This probably occurred, because particulate matter and sulfur dioxide tend to be highly correlated, a fact that occurs with the concentrations of $\mathrm{SO}_{2}$ and $\mathrm{PM}_{10}$ found in São José dos Campos. On the other hand, recorded stroke hospitalizations strongly correlated with the concentrations of $\mathrm{PM}_{10}$.

The increased relative risk of hospitalization for stroke was around $12 \%$ due to an increase in the concentration of $10 \mu \mathrm{g} / \mathrm{m}^{3}$. It should be noted that concentrations of $\mathrm{PM}_{10}$ are relatively spatially homogeneous, within a metropolitan area and environmental factors measured from a central location, correlate well with personal exposure.

The findings of the effects of this pollutant in stroke hospitalizations coincides with the findings of hospitalizations for respiratory and cardiovascular diseases in adults reported in other studies conducted in São Paulo 8,13.

In a study conducted in Taiwan 4 , where the average concentration of $\mathrm{PM}_{10}$ was three times higher, and the average concentration of $\mathrm{SO}_{2}$ was seven times higher than concentrations reported in São José dos Campos during this study, the effects of these pollutants were also associated with stroke hospitalizations.

In a North American study 5, where the average concentration of $\mathrm{PM}_{10}$ was similar to those concentrations found in São José dos Campos, ischemic stroke hospitalizations were associated with exposure to this pollutant on concurrent days (lag 0 ), but not in the two previous days (lag 1) and (lag 2). Findings from this American study, showed that exposure to $\mathrm{PM}_{10}$ were not associated with hemorrhagic stroke. But, exposure to particulate matter was associated with a $52 \%$ increase in the risk of death, for patients who had stroke 15 .

The mechanisms that can lead to the genesis of stroke might be associated with one or more of the following conditions; systemic inflammatory response, increased fibrinogen, the Von Willebrand factor and activity of the autonomic nervous system. 
Possible limitations of this study may be related to the misclassification and coding of stroke diagnosis, unrecognized occurrence of stroke and non-hospitalized individuals, with the onset of stroke symptoms in the days prior to admission.

There was no measurement of individual exposure to pollutants, because it was an environmental study. Furthermore, no information was obtained in regards to smoking or indoor pollution.

The missing data entries on pollutant concentrations were not relegated to only one specific time period, but were distributed throughout the entire study period, possibly compromising the results. The pollutant with the highest number of missing data entries was $\mathrm{SO}_{2}$.

The use of GLM in place of the GAM may also have affected the study, because the GAM incorporates information about seasonal changes and trends between meteorological variables and hospital admissions. GLM requires a smaller number of explanatory variables and detects a greater number of associations 13 .

Another limitation of the data analysis is, that incidence of stroke is considered a rare event. During this study, there were many days with zero stroke hospitalizations.

The results presented in this study represent an approximation of the quantitative impact of air pollution on human health. It is important to note, that the outcomes studied here, were a result of stroke hospitalization data. Hospitalizations due to stroke are just one of the many effects caused by air pollution. This study used secondary data to calculate the coefficients and relative risks in stroke hospitalizations resulting from the increased level of air pollution observed. The data used here is from stable and reliable sources. Data from these sources is widely used in scientific and technical work.

In regards to data collected from stroke hospitalization records in the public health care system, the results presented here reflect the effects of air pollution on the population that uses this system, which accounts for a majority of the Brazilian population.

It is important to point out, that even at concentrations below, those recommended by CONAMA (http://www.mma.gov.br/port/ conama $/$ legipesq.cfm?tipo $=3 \&$ numero $=03 \&$ an $o=1990 \&$ texto $=$, accessed on 20/Oct/2011), one can associate an increased incidence of stroke hospitalizations with exposure to elevated concentrations of $\mathrm{PM}_{10}$. This is an environmental concern of much gravity and incurs enormous financial and social costs.

It is hoped that the data presented here, serves as a tool of better understanding, in regards to the impact of air pollution on human health.

\section{Resumo}

Alguns dos efeitos da poluição ambiental na saúde humana são conhecidos, destacando aqueles nos sistemas respiratório e cardiovascular. Este trabalho tem por objetivo estimar esses efeitos na gênese das internações por acidente vasculoencefálico. Foi um estudo ecológico realizado com dados de internações da cidade de São José dos Campos, São Paulo, Brasil, relativos aos diagnósticos de acidente vascular cerebral, entre 1 o de janeiro de 2007 e 30 de abril de 2008. Os poluentes estudados foram material particulado, dióxido de enxofre e ozônio. Utilizando-se de modelo linear generalizado da regressão de Poisson, foi possível identificar exposição ao material particulado, no mesmo dia, como associado à internação por acidente vasculoencefálico (RR = 1,013; IC95\%: 1,001-1,025). O aumento de $10 \mu \mathrm{g} / \mathrm{m} 3$ desse poluente aumenta o risco de internação em 12\% (RR = 1,137; IC95\%: 1,014-1,276). Assim, foi possível identificar o material particulado, no modelo multipoluente, como associado à internação por acidente vasculoencefálico numa cidade de porte médio, como São José dos Campos.

Poluição do Ar; Acidente Cerebral Vascular; Material Particulado; Dióxido de Enxofre; Ozônio 


\section{Contributors}

L. F. C. Nascimento contributed towards the elaboration of this project, discussion of data and drafting the final version of the article. J. B. Francisco, M. B. R. Patto and A. M. Antunes helped with data preparation and in drafting the final version of the article.

\section{References}

1. Olmo NRS, Saldiva PHN, Braga ALF, Lin CA, Santos UP, Pereira LAA. A review of low-level air pollution and adverse effects on human health: implications for epidemiological studies and public policy. Clinics 2011; 66:681-90.

2. Nascimento LFC. Air pollution and cardiovascular hospital admissions in a medium-sized city in São Paulo State, Brazil. Braz J Med Biol Res 2011; 44:720-4.

3. Oliveira MS, Ponce de Leon A, Mattos IE, Koifman S. Differential susceptibility according to gender in the association between air pollution and mortality from respiratory diseases. Cad Saúde Pública 2011; 27:1827-36.

4. Tsai SS, Goggins WB, Chiu HF, Yang CY. Evidence for an association between air pollution and daily stroke admissions in Kaohsiung, Taiwan. Stroke 2003; 34:2612-6.

5. Wellenius GA, Schwartz J, Mittleman MA. Air pollution and hospital admissions for ischemic and hemorrhagic stroke among Medicare beneficiaries. Stroke 2005; 36:2549-53.

6. Oudin A, Strömberg U, Jakobson K, Stroh E, Björk J. Estimation of short-term effects of air pollution on stroke hospital admissions in Southern Sweden. Neuroepidemiology 2010; 34:131-42.

7. Johnson JYM, Rowe BH, Villeneuve PJ. Ecological analysis of long-term exposure to ambient air pollution and incidence of stroke in Edmonton, Alberta, Canada. Stroke 2010; 41:1319-25.

8. Cendon S, Pereira LAA, Braga ALF, Conceição GMS, Cury-Junior A, Romaldini H, et al. Air pollution effects on myocardial infarction. Rev Saúde Pública 2006; 40:414-9.

\section{Acknowledgments}

L. F. C. Nascimento wishes to thank FAPESP for financial support (grant number 2011/06647-0).
9. Nascimento LFC, Pereira LAA, Braga ALF, Modolo MCC, Carvalho Jr. JA. Effects of air pollution on children's health in a city in Southeastern Brazil. Rev Saúde Pública 2006; 40:77-82.

10. Nelder JA, Wedderburn RWM. Generalized linear models. J R Stat Soc A 1972; 135:370-84.

11. Braga ALF, Conceição GMS, Pereira LAA, Kishi H, Pereira JCR, Andrade MF, et al. Air pollution and pediatric respiratory admissions in São Paulo, Brazil. J Environ Med 1999; 1:95-102.

12. Gouveia N, Freitas CU, Martins LC, Marcilio IO. Hospitalizações por causas respiratórias e cardiovasculares associadas à contaminação atmosférica no Município de São Paulo, Brasil. Cad Saúde Pública 2006; 22:2669-77.

13. Conceição GMS, Saldiva PHN, Singer JM. GLM and GAM model for analyzing the association between atmospheric pollution and morbidity-mortality markers: an introduction based on data from the city of São Paulo. Rev Bras Epidemiol 2001; 4: 206-19.

14. Arbex MA, Saldiva PHN, Pereira LAA, Braga ALF. Impact of outdoor biomass air pollution on hypertension hospital admissions. J Epidemiol Community Health 2010; 64:573-9.

15. Maheswaran R, Pearson T, Smeeton NC, Beevers $\mathrm{SD}$, Campbell MJ, Wolfe CD. Impact of outdoor air pollution on survival after stroke: populationbased cohort study. Stroke 2010; 41:869-77.

Submitted on $03 / \mathrm{Jan} / 2011$

Final version resubmitted on 21/Dec/2011

Approved on 15/Mar/2012 